\title{
EDUCATIONAND TRAINING An investigation into hospital prescribers' knowledge and confidence to provide high-quality, sustainable respiratory care
}

\author{
Authors: Sarah C Walpole, ${ }^{A}$ Katherine Smith, ${ }^{B}$ Joseph McElvaney, ${ }^{C}$ Jill Taylor, $^{D}$ Simon Doe ${ }^{E}$ and Hilary Tedd ${ }^{E}$
}

The number and range of inhaler combinations and brand names has increased significantly over recent years, making prescribing more complex. Inhalers contribute $3 \%$ of the NHS's carbon footprint, therefore appropriate inhaler prescribing, use and disposal could contribute significantly towards the NHS's target of net zero carbon emissions by 2040 .

We developed a survey to assess prescriber knowledge of inhaled medications, inhalation devices and environmental impacts of inhalers. One-hundred and two secondary care prescribers from one NHS trust responded. Knowledge of the contents and device types of inhalers, and of the environmental impacts of inhalers was lacking. Only $9 \%$ of respondents discuss the environmental impact of inhalers with patients and $13 \%$ have discussed inhaler disposal with patients, but $46 \%$ of respondents expressed that they would educate patients about the environmental impacts of inhalers if they were provided with education and support to do so.

KEYWORDS: respiratory, inhalers, environment, sustainability, prescribing

DOI: 10.7861/fhj.2020-0251

\section{Introduction}

In October 2020, the NHS launched a practical and evidencebased strategy to achieve a net zero carbon healthcare service. It committed to a $51 \%$ carbon emissions reduction by 2025 (on a 2007 baseline) with NHS England's report stating that the

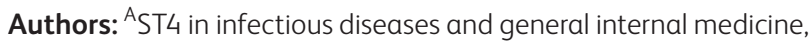
The Newcastle upon Tyne Hospitals NHS Foundation Trust, Newcastle upon Tyne, UK; ${ }^{B}$ trust doctor, The Newcastle upon Tyne Hospitals NHS Foundation Trust, Newcastle upon Tyne, UK; ${ }^{C}$ medical student, Newcastle University, Newcastle upon Tyne,

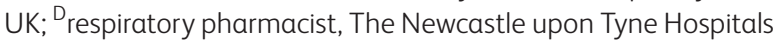
NHS Foundation Trust, Newcastle upon Tyne, UK; ${ }^{E}$ consultant in respiratory medicine, The Newcastle upon Tyne Hospitals NHS Foundation Trust, Newcastle upon Tyne, UK approach will need to be iterative and adaptive. ${ }^{1}$ This implies a need for local leadership, innovation and stewardship.

Sustainable healthcare refers to the ability of services to provide for health needs without compromising the ability of others (including but not limited to future generations) to meet their health needs. There are three dimensions of sustainability: economy, society and the environment. ${ }^{2}$

Inhalers contribute an estimated $3 \%$ of the NHS's carbon footprint. ${ }^{3}$ The footprint of dry powder inhalers (DPIs) is $8 \mathrm{~g} \mathrm{CO}_{2}$ equivalent (eq) / dose, compared with 82-119 $\mathrm{g} \mathrm{CO}_{2}$ eq/dose for metered dose inhalers (MDIs), more than 10 times greater. ${ }^{4}$ Reducing unnecessary MDI prescribing is one target area for carbon reduction in the health service. A study in 2016 calculated the doses left in over 2,000 inhalers after disposal. In MDIs, a mean of $48 \%$ of doses were unused, compared with just $27 \%$ in DPIs. ${ }^{5}$ DPIs more frequently have a dose counter, which enables the patient to accurately recognise when their inhaler requires replacement. ${ }^{6}$ Within the general practice (GP) contract update for 2021, which guides UK primary care, there are targets (with associated financial rewards) for reducing the carbon footprint of inhaler prescribing. ${ }^{7}$ This has potential clinical benefits too; inhaler technique for MDIs is more difficult to accurately teach. MDIs, apart from breath actuated MDIs, should ideally be used with a spacer, whereas DPIs can be taken directly.

High-quality, sustainable respiratory care necessarily incorporates effective patient engagement, which will be best achieved through a proactive multidisciplinary team approach including pharmacists, nurses, doctors and other healthcare professionals (HCPs). During 2020, the National Institute for Health and Care Excellence (NICE) has updated a decision aid to enable patients to express their priorities and preferences in regard to inhaler prescriptions. ${ }^{8}$ In order to facilitate patient engagement, clinicians need to be informed, up-to-date and able to discuss with patients the breadth of issues related to inhaler prescriptions. We explored the main challenges and opportunities to improve the quality and sustainability of respiratory care in our NHS trust.

\section{Aim}

We wished to explore prescriber knowledge and confidence on key aspects of inhaled therapies, including inhaler constituents, inhaler technique and environmental impacts of inhalers. 


\section{Methods}

A survey was designed and presented on Google Forms. It was piloted initially with a small number of prescribers $(n=10)$ based in other trusts, with minor revisions made as a result. To allow the opportunity of an educational intervention, answers to knowledge questions were displayed to respondents on completion.

The final survey (supplementary material S1) was disseminated electronically to a wide range of prescribers, including pharmacists, junior medical and surgical staff, senior doctors in non-medical specialties (including orthopaedics and neurosurgery), senior doctors in medical non-respiratory specialties and respiratory specialists. Emails inviting prescribers and pharmacists to complete the survey were sent out via rota coordinators' email lists and via pharmacists' email lists. Reminders to complete the survey were delivered verbally by visiting wards and talking to prescribers and via WhatsApp groups where available.

Results were downloaded from Google Forms into MS Excel spreadsheets and all analyses were carried out within these spreadsheets. Descriptive analysis of total responses and responses by sub-group was undertaken.

\section{Ethical considerations}

Caldicott guardian approval was gained prior to starting these evaluations.

\section{Results}

One-hundred and two prescribers responded to the staff survey over a 4-week period: 21/102 (20.6\%) foundation doctors, 22/102 (21.6\%) pharmacists and pharmacist prescribers, 32/102 (31.4\%) other junior doctors, $8 / 102(7.8 \%)$ respiratory consultants and $8 / 102(7.8 \%)$ consultants from other specialties (Fig 1).

$58 / 102(56.9 \%)$ respondents had previously or currently worked within a respiratory setting. $88 / 102(86.3 \%)$ said that they prescribe inhalers and, of these, $45 / 88(51.1 \%)$ routinely initiated or changed inhaler prescriptions. In terms of confidence in assessing a patient's inhaler technique, 72/102 (70.6\%) respondents said they were confident to do this; the proportion per professional group is shown in Table 1.

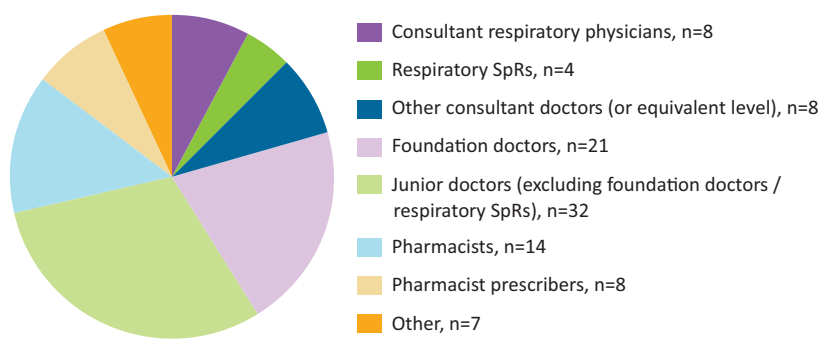

Fig 1. Staff survey respondents by occupation. $\mathrm{SpR}=$ specialty registrar.

In assessing clinicians' knowledge of inhaler types, an initial question asked respondents to match six inhalers described by brand name to the drug classes that they contain. A second question asked them to match the same six inhalers to the device type: MDI or DPI. The median score for both questions was $8 / 12$ $(66.7 \%)$. Respiratory physicians and pharmacists performed best while non-respiratory consultants achieved the lowest scores (Table 2). In free text comments, respondents discussed the challenges of keeping up-to-date with the latest available inhalers. A consultant said: 'There is a plethora of inhaled devices available which is confusing for patients and HCPs alike.

On questions relating to the environmental impact of inhalers (Table 3), respondents had a mean score of 0.9/3 (29.7\%; Fig 2). $2 / 102(2.0 \%)$ respondents answered all three questions correctly. $13 / 102(12.7 \%)$ thought that DPIs had a higher carbon footprint than MDIs.

$47 / 102(46.1 \%)$ of respondents feel that they would be confident to discuss lower-carbon inhaler choices with patients if given further support, such as training, senior guidance or a patient decision tool. $42 / 102(41.2 \%)$ do not feel confident to discuss this with patients. $9 / 102$ (8.8\%) already speak to patients about this or would be willing to without further support (Fig 3).

$13 / 102(12.7 \%)$ have previously discussed inhaler recycling with patients. 28/102 (27.5\%) were aware that recycling is possible but do not discuss it with patients. 57 (55.9\%) did not know that inhalers can be recycled at pharmacies (Fig 4).

Table 1. Clinicians responsible for initiating and changing inhalers

\begin{tabular}{|c|c|c|c|}
\hline & $\begin{array}{l}\text { Stated that they } \\
\text { are responsible for } \\
\text { initiating inhalers, } n(\%)\end{array}$ & $\begin{array}{l}\text { Stated that they } \\
\text { are responsible for } \\
\text { changing inhalers, } n(\%)\end{array}$ & $\begin{array}{l}\text { Feel confident to } \\
\text { assess a patient's } \\
\text { inhaler technique, n (\%) }\end{array}$ \\
\hline Respiratory physicians (consultant or $\mathrm{SpR}$ ), $\mathrm{n}=12$ & $10(83.3)$ & $12(100.0)$ & $12(100.0)$ \\
\hline Other consultant doctors (or equivalent level), $n=8$ & $3(37.5)$ & $3(37.5)$ & $5(62.5)$ \\
\hline $\begin{array}{l}\text { Junior doctors (excluding foundation doctor / } \\
\text { respiratory SpR), } n=32\end{array}$ & $8(25.0)$ & $7(21.9)$ & $20(62.5)$ \\
\hline Foundation doctors, $n=21$ & $4(19.0)$ & $5(23.8)$ & $16(76.2)$ \\
\hline Pharmacists, $n=22$ & $3(13.6)$ & $8(36.4)$ & $16(72.7)$ \\
\hline $\begin{array}{l}\text { Other (two nurses, one physician associate and four } \\
\text { other physicians), } n=7\end{array}$ & $2(28.6)$ & $3(42.9)$ & $3(42.9)$ \\
\hline Total, $n=102$ & $30(29.4)$ & $38(37.3)$ & $72(70.6)$ \\
\hline
\end{tabular}


Table 2. Median inhaler knowledge score by clinician group

\begin{tabular}{|c|c|c|c|}
\hline & $\begin{array}{l}\text { Ability to match } \\
\text { inhaler to device type, } \\
\text { median score out of } 6\end{array}$ & $\begin{array}{l}\text { Ability to match } \\
\text { inhaler to drug class, } \\
\text { median score out of } 6\end{array}$ & $\begin{array}{l}\text { Total knowledge } \\
\text { score, median } \\
\text { score out of } 12\end{array}$ \\
\hline Respiratory SpRs & 5.0 & 6.0 & 11.0 \\
\hline Pharmacists & 5.0 & 5.0 & 11.0 \\
\hline Consultant respiratory physicians & 4.5 & 6.0 & 10.5 \\
\hline Junior doctors (excluding foundation doctors / respiratory SpRs) & 3.0 & 4.0 & 7.5 \\
\hline Foundation doctors & 4.0 & 4.0 & 7.0 \\
\hline Other consultant doctors (or equivalent level) & 0.5 & 3.0 & 4.0 \\
\hline All respondents & 4.0 & 5.0 & 8.0 \\
\hline
\end{tabular}

\section{Discussion}

A recent study found that changing the ratio of DPI:MDI prescriptions in England to that in Sweden would reduce the NHS's carbon footprint by $2.6 \% .{ }^{9}$ Optimising inhaler prescribing through MDI to DPI switches and minimising wastage of inhaled medication doses could thus make a significant contribution towards the NHS meeting its commitment to reduce direct emissions to net zero by 2040. There are potential financial gains to pursuing this strategy. Although switching from MDIs to DPIs increases costs for some inhalers, particularly salbutamol (the most commonly used short-acting beta agonist (SABA)), an overall cost saving would be achieved by a wholesale change to DPIs. In addition, minimising wastage (due to incorrect technique and early disposal of inhalers before they are empty) offers the promise of further savings. ${ }^{10}$ Realising these environmental and financial benefits, and associated improvements in control of respiratory disease, will only be possible if prescribers are aware of the issues and have appropriate knowledge of available medications and devices. A literature search identified no studies of clinicians' knowledge of this topic. This study highlights current deficiencies in these key areas, including, crucially, environmental impacts of inhalers.

Clinicians performed better when identifying which drug class an inhaler contains than which device type it is (DPI or MDI). Nonrespiratory consultants were less likely to be able to identify inhaler

Table 3. Knowledge of the environmental impact of inhalers

\begin{tabular}{lll}
$\begin{array}{l}\text { Question } \\
\begin{array}{l}\text { Relative size of carbon } \\
\text { footprint of MDIs } \\
\text { compared with DPIs }\end{array}\end{array}$ & $\begin{array}{l}\text { MDI footprint 18 } \\
\text { times DPI footprint }\end{array}$ & $\begin{array}{l}\text { Correct } \\
\text { answers, n (\%) }\end{array}$ \\
$\begin{array}{l}\text { Average proportion of } \\
\text { doses left unused in }\end{array}$ & $\begin{array}{l}\text { Average 48\% of } \\
\text { doses left unused } \\
\text { in MDI }\end{array}$ & 18/102 (17.6) \\
$\begin{array}{l}\text { MDIs at disposal } \\
\begin{array}{l}\text { Proportion of NHS } \\
\text { carbon footprint } \\
\text { represented by inhalers }\end{array}\end{array}$ & $\begin{array}{l}\text { Inhalers represent } \\
4 \% \text { of NHS carbon }\end{array}$ & $31 / 102(30.4)$ \\
\hline
\end{tabular}

DPIs $=$ dry powder inhalers; MDIs $=$ metered dose inhalers.

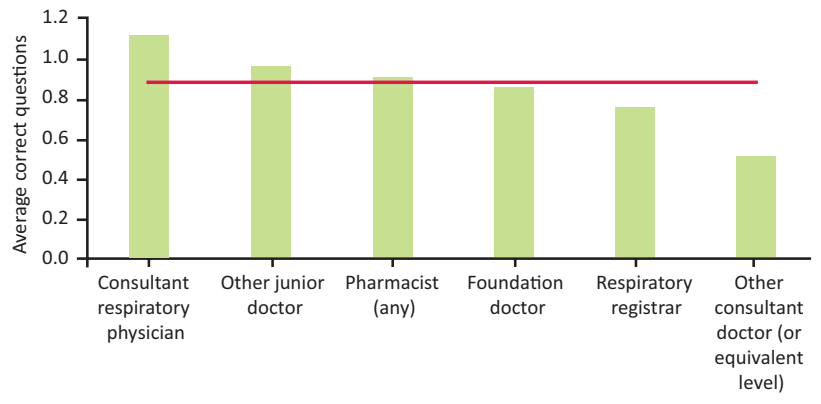

Fig 2. Knowledge of the environmental impact of inhalers by clinician group. Red line $=$ mean score across all groups.

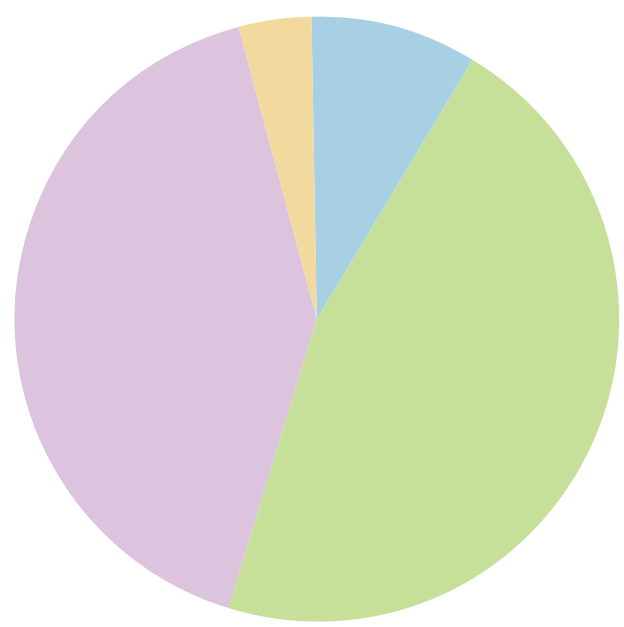

Already do, or would with further support Yes, with further support such as specific training, senior support or a patient decision tool No

Other

Fig 3. Response to the question: 'Would you feel confident to discuss lower-carbon inhaler choices with a patient?' 


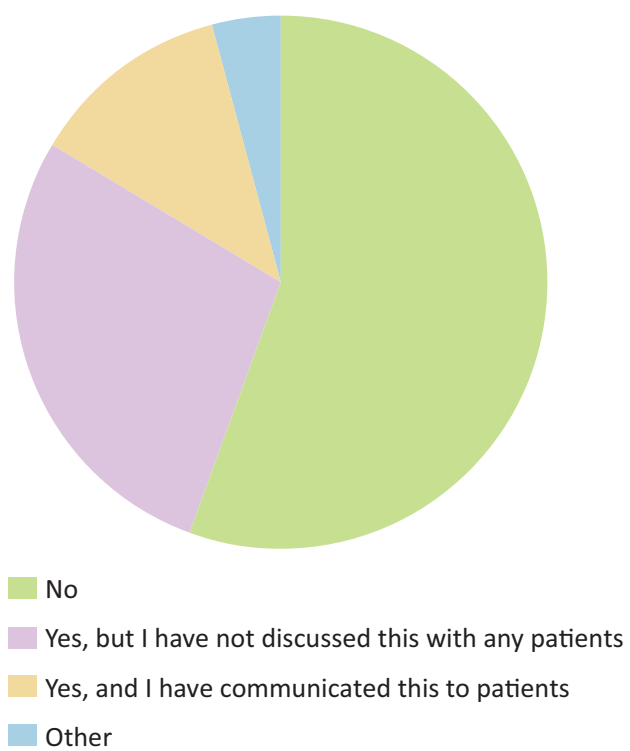

Fig 4. Response to the question: 'Did you know that empty inhalers can be recycled by most pharmacies?'

medications and devices, while respiratory physicians, pharmacists and other junior doctors achieved the highest scores on average. Regarding assessment of technique, non-respiratory consultants were also among the least confident at assessing technique despite being responsible for changing and initiating inhalers.

In order to improve quality of patient care and sustainability of respiratory care, it is important that prescribers who are re-prescribing inhalers or prescribing inhalers for the first time have a good knowledge of (or access to resources to check) characteristics of inhalers in each class (long-acting muscarinic antagonist (LAMA) / long-acting beta-2-agonist (LABA) / inhaled corticosteroid (ICS) and combinations), such as carbon footprint and technique required for each device type. Reducing the environmental footprint of respiratory care will require education and adaptations to guidelines and practice across primary and secondary care and inclusive of all health professionals, inclusive of all those who prescribe, review prescriptions, check inhaler technique and educate patients. An opportunity exists to help clinicians and patients develop a deeper understanding of these issues; $46 \%$ of respondents would consider discussing the environmental impact of inhalers with patients given the appropriate support. Examples such as a national UK project training 'air pollution champions' has explored which environmental issues are appropriate to cover in discussion with patients and how best to approach and frame these issues. ${ }^{11}$

Limitations of the study include a lack of validated scales on which to assess participants' knowledge and confidence. The sample size was small, but did include respondents from a wide range of different professions. Participation was voluntary and reminders to complete the survey were delivered informally to those known to or working at a similar level to the authors, therefore introducing some responder bias. A strength was the $100 \%$ completion rate of those who did take part (zero responders left a question unanswered). This study did not explore knowledge of soft-mist inhalers (SMIs) due to the fact that they make up a small proportion of available inhalers and have low carbon footprint compared with MDIs. ${ }^{12}$

\section{Conclusion}

This data has identified significant knowledge gaps in key aspects of inhaler prescribing including inhaler constituents and class (MDI vs DPI). In addition, awareness of the environmental impact of inhaler choice is an area that should be targeted.

This is especially important in trying to meet the challenge of promoting high-quality, sustainable respiratory care. In response, a sustainable respiratory care working group has been established in our trust. We have developed an informational poster displaying inhalers' drug class, brand names and device type and further educational interventions are planned. We are building connections between primary and secondary care to ensure that high-quality respiratory care is promoted throughout patients' care and treatment.

\section{Supplementary material}

Additional supplementary material may be found in the online version of this article at www.rcpjournals.org/fhj:

S1 - All survey questions that were presented in the online survey on Google Forms.

\section{Acknowledgements}

Thanks to Dr Adam Potts, junior doctor; Dr Graham Burns, respiratory consultant; James Steele, medical student; Dr Jim Macfarlane, respiratory consultant; Hannah Willoughby, pharmacist; Dr Georgina Sowman, GP; Dr Matt Sawyer, GP; and Laura Middlemass, sustainability officer.

\section{Conflicts of interest}

Simon Doe has received speaker fees from GSK and Novartis.

\section{References}

1 NHS England. The NHS Long Term Plan. NHS, 2019. www. longtermplan.nhs.uk/wp-content/uploads/2019/08/nhs-long-termplan-version-1.2.pdf

2 Lombardi DR, Porter L, Barber A, Rogers CDF. Conceptualising sustainability in UK urban regeneration: a discursive formation. Urban Stud 2011;48:273-96.

3 NHS England, NHS Improvement. Delivering a 'net zero' National Health Service. NHS, 2020. www.england.nhs.uk/greenernhs/ publication/delivering-a-net-zero-national-health-service

4 Panigone S, Sandri F, Ferri R et al. Environmental impact of inhalers for respiratory diseases: decreasing the carbon footprint while preserving patient-tailored treatment. BMJ Open Respir Res 2020;7:e000571.

5 GSK, NHS Grampian. Complete the cycle: NHS Grampian inhaler analysis. GSK, 2016 [unpublished].

6 Conner JB, Buck PO. Improving asthma management: the case for mandatory inclusion of dose counters on all rescue bronchodilators. J Asthma 2013;50:658-63.

7 NHS England. Update to the GP contract agreement 2020/21 2023/24. NHS, 2020. www.england.nhs.uk/wp-content/ uploads/2020/03/update-to-the-gp-contract-agreement-v2-updated.pdf

8 National Institute for Health and Care Excellence. Patient decision aid: Inhalers for asthma. NICE, 2020. www.nice.org.uk/ 
guidance/ng80/resources/inhalers-for-asthma-patient-decision-aidpdf-6727144573

9 Janson C, Henderson R, Löfdahl M et al. Carbon footprint impact of the choice of inhalers for asthma and COPD. Thorax 2020;75:82-4.

10 Wilkinson AJK, Braggins R, Steinbach I, Smith J. Costs of switching to low global warming potential inhalers. An economic and carbon footprint analysis of NHS prescription data in England. BMJ Open 2019;9:e028763.

11 Global Action Plan. Mobilising health professionals on air pollution. Global Action Plan, 2020. www.cleanairhub.org.uk/mobilisinghealth-professionals [Accessed 30 November 2020].
12 Hänsel M, Bambach T, Wachtel $H$. Reduced environmental impact of the reusable Respimat Soft Mist inhaler compared with pressurised metered-dose inhalers. Adv Ther 2019:36:2487-92.

Address for correspondence: Dr Sarah Walpole, Department of Infectious diseases, Royal Victoria Infirmary, Queen Victoria Road, Newcastle upon Tyne NE1 4LP, UK. Email: sarah.walpole1@nhs.net

Twitter: @sarahcwalpole 